\title{
RECONVERSIÓN, DAÑO Y \\ ABANDONO EN LA CIUDAD \\ DE LOTA'
}

\author{
RECONVERSION, DAMAGE AND ABANDONMENT \\ IN THE CITY OF LOTA
}

\section{JUAN CARLOS RODRÍGUEZ TORRENT² PATRICIO MEDINA HERNÁNDEZ 3}

\section{RESUMEN}

Lota es una ciudad minera y monoproductora de riqueza energética, la que desde el siglo XIX y hasta la mitad del siglo XX tuvo impacto en el desarrollo económico y territorial de Chile. En ella se expresa la versión local de la Revolución Industrial y las relaciones sociales capitalistas de producción; se constituye un sujeto histórico con identidad laboral y de clase, el cual se distingue por su forma de trabajo subterráneo, lo que da origen a una cultura laboral y una épica singular; y se forja una tradición organizativa y sindical que denunció las condiciones de trabajo y de vida de la población local. Será la decadencia del valor del mineral y el aumento de los costes de producción lo que impuso el cierre de los piques, después de casi 150 años de explotación, configurando un proceso de anulación definitiva de la actividad y del saber que, por una parte, obliga a la formulación de un Plan de Reconversión y, por otra, deja a los cesados y a la ciudad en una condición marginal y residual. Este trabajo explora argumentativamente las dificultades para el reemprendimiento productivo postcarbón en un mundo patriarcal y aprecia antropológicamente la pérdida, los problemas ligados a la autoimagen y los vacíos rituales propios de un mundo experto, social y económicamente precario, de baja calificación, planteando que la reescritura biográfica trata de un problema simbólico más que técnico.

Palabras clave: Trabajo, minería, tradición, épica, reconversión.

${ }^{1}$ Este trabajo es producto del Proyecto Fondecyt 1095037, "Memorias, imaginarios y ruinas en ciudades de la utopía industrial: Lota y Taltal".

${ }^{2}$ Dr. en Ciencias Antropológicas. Antropólogo de la Escuela de Diseño, Universidad de Valparaíso. Valparaíso, Chile. E-mail: juancarlosrodriguezt@yahoo.com

${ }^{3}$ Antropólogo de la Escuela de Psicología, Pontificia Universidad Católica de Valparaíso. Valparaíso, Chile. E-mail: pmedinahernandez@yahoo.es 


\begin{abstract}
Lota is a mining city and mono-producer of energy wealth which, from the nineteenth century up to the middle of the twentieth century, had an impact on the economic and territorial development of Chile. It expresses the local version of the Industrial Revolution and capitalist social relations of production. A historical subject with labor and class identity, distinguished by the form of working underground was constituted, giving rise to a singular workplace culture and epic, and forging a union and organizing tradition that denounced the unfair conditions of work and life of the local population. The decline of the value of coal and increased production costs dictated the closure of the mining shafts after nearly 150 years of operation. This obliged on the one hand, the formulation of a Plan of Conversion and on the other, would leave the newly unemployed workers and the city itself to be dismissed as marginal and residual. This paper explores the difficulties for the resumption of post coal production in a patriarchal world and appreciates anthropologically the loss, the problems associated with selfimage and the rituals associated with precarious social and economic conditions and low-skilled workers. It is proposed that a biographical rewriting is more of a symbolic problem than a technical one.
\end{abstract}

Keywords: Labor, mining, tradition, epic, conversion.

Recibido: 06.04.11. Aceptado: 21.07.11.

\title{
I. LOTA: ANTECEDENTES DE UNA TRAYECTORIA CITADINA Y MINERA
}

I

OTA, "PEQUEÑO caserío" en mapudungun, partió siendo un enclave de trabajo carbonífero con 125 operarios en 1852, el que en su primer centenario ya contaba con 10.000 obreros, lo que la constituía en una ciudad "atractiva y floreciente" (Astorquiza, 1952). Pasó de ser una desolada estación de ferrocarril "de calles desnudas y destrozadas a una urbe pavimentada y limpia” (Galleguillos, 1952). La ciudad originaria, con atributos de una company town, fue construida para evitar el difícil traslado de trabajadores desde las zonas agrícolas, llegando a tener una población hacia 1970 de unas 80.000 personas. Se establece como la primera ciudad industrial del país, siendo parte de una macrozona carbonífera que incluye a las ciudades de Coronel, Lebu y Curanilahue; de esta manera favoreció la constitución de los cimientos de la nación, producto de la riqueza que fue capaz de generar. Esta afirmación se puede recoger en términos de antecedentes histórico documentales, de historia oral, etnográficos, etnológicos y fotográficos, como también desde una arqueología industrial. Las fuentes y los soportes configuran un corpus que nos habla de distintos procesos, mo- 
mentos, aceleraciones y contracciones de su trayectoria, los que la avalan como tal.

En torno a la ciudad y la producción minera se realizaron movimientos de población mapuche, campesina y extranjera; se implementaron un conjunto de tempranas inversiones de capital y esfuerzos técnicos de importante magnitud para operar piques y bocaminas. En la última parte del siglo XIX y comienzos del XX se constituye como una ciudad emergente con sus servicios relativos tanto a las demandas industriales como a las domésticas de sus habitantes. Su desarrollo y actividad extractiva trascienden su territorio y se irradia paradigmáticamente conectándose con el norte, centro y sur del país, ya que Lota fue, por antonomasia, la ciudad monoproductora de riqueza energética. Por casi un siglo tiene presencia nacional, tanto en lo terrestre como en lo oceánico, alimentando con su carbón las fundiciones de cobre, la industria, los ferrocarriles y los vapores. Fue también un importante puerto para los navíos que remontaban el Estrecho de Magallanes, llegando a unos 200 anualmente, los que recalaban para abastecerse del mineral para sus calderas.

Dentro de su distinción como enclave industrial y habitacional, destacan: la primera planta hidroeléctrica de Chile, Chivilingo, la cual data de 1897, diseñada por Thomas Alva Edison; el alumbrado público, el alcantarillado, la calefacción de las viviendas, las instalaciones portuarias, el primer ferrocarril eléctrico de Chile con un tendido ferroviario que conecta a las distintas secciones de la Compañía, los ascensores para conducir el personal en los piques, la primera planta telefónica del país ${ }^{4}$, la telefonía interna al interior de la minas y el tren subterráneo para movilizar a los trabajadores, conducir materiales y extraer el mineral. En Lota no sólo encontramos la empresa principal que explota carbón, la Compañía Industrial de Lota, sino también se encuentra presente la Sociedad Agrícola y Forestal Colcura, que explota recursos forestales; la fábrica de cerámica Refractarios Lota Green, S.A. y la Empresa de Administración de Flota que transporta el mineral a través de la Compañía Naviera Arauco S.A. Las empresas son complementarias y responden a la misma organización económica, lo que pone a Lota a la vanguardia del movimiento fabril.

La intensidad de la actividad contó, para la extracción de carbón, con unos 6.200 trabajadores en tiempos de la administración de la familia Cousiño -en un universo de 10.000 dedicados al rubro en el siglo XIX-, unos 18.000 trabajadores en la década de 1950, 16.000 en 1973, 5.971 en

\footnotetext{
${ }^{4}$ Inaugurada sólo un año después de ser inventada la telefonía.
} 
1982 y en 1990, menos de 5.000. Cifras que deben interpretarse a la luz de las vicisitudes sufridas por la industria carbonífera asociadas a los ritmos de producción y fases de declinación de acuerdo a tres elementos estructurantes: la matriz energética del país, que da cuenta de los cambios en la demanda ligados al desarrollo de la industria; la incorporación de tecnología más eficiente; y los costes de producción, lo que tiene incidencia en la demanda de fuerza de trabajo y en la generación de la riqueza en la ciudad ${ }^{5}$.

El poblamiento que da paso del originario campamento a la ciudad minera se perfila con los atributos de la revolución industrial y manifiesta el modelo de producción capitalista en su versión chilena. Reconocer estos atributos, permite avalar que en Lota se desarrolla en torno al trabajo la organización más fuerte que haya podido desarrollar el capital chileno (Astorquiza, 1952, p. 15), dando origen a lo que sería el primer holding nacional de propiedad de la familia Cousiño; y es en este enclave productivo donde se genera la salarización, la temprana inserción de los jóvenes al mundo laboral y el trabajo infantil, integrados a verdaderas cadenas humanas $^{6}$, lo que termina imponiéndose como pauta de socialización intergeneracional y tradición familiar; los trabajadores indígenas y campesinos reclutados son sometidos a una maquinización y adiestramiento corporal y a una cultura horaria cronológica, propia del rigor de la industrialización como precondición para la integración social.

Señala Hernán Venegas de acuerdo al texto de Francisco Marcial Aracena, que data de 1884:

es verdaderamente pintoresco presenciar el trabajo de ochenta o cien niños empleados en esta sección. Las diversas operaciones tan hábilmente combinadas y distribuidas en los distintos grupos de niños de ocho a catorce años de edad, que todos al fin, o el trabajo de todos juntos, se asemeja a una gran máquina a vapor puesta en movimiento, y siendo cada una de las piezas de esta gran máquina representada por un grupo de muchachos más o menos numerosos (Venegas, 2008, p. 65).

\footnotetext{
${ }^{5}$ Las cifras entregadas por Aravena y Betancur (1999) son claras: en 1974 el coste de producción de una tonelada era de 44 dólares, y en 1987 de 52,07 dólares, cuestión que está asociada a baja productividad y sobredotación de personal.

${ }^{6}$ Entre las personas de más edad es fácil encontrar referencias a los años 30 en los que el ingreso al mundo del trabajo se producía a los 12 años. Esto significaba un aprendizaje en torno al trabajo minero desde cuestiones muy menores como los mandados o labores de apir (sin especialización) a las cuestiones más complejas como disparador o mayordomo.
} 
La puesta en marcha de la actividad carbonífera subterránea hacia 1875, una vez agotados los recursos mineros en superficie, impone la necesidad de resolver cuestiones de orden técnica, tales como la fortificación, la ventilación y el desagüe de las galerías, para una explotación eficiente y de menor riesgo. También, conjugar ese mundo íntimo del interior de la mina, oscuro, que arranca de las entrañas de la tierra y del mar, con la vida de la superficie, ésa donde brota la lluvia, el sol, la luz, la del día a día, en la que se vive el sino de la reproducción social y biológica. En esta pretensión de armonización entre el desarrollo económico y la rentabilidad del complejo industrial, por una parte, y la vida diaria de las personas, por otra, es donde debe observarse que Lota nace capitalista y fijar la mirada en perspectiva, la observación de los hitos más importantes de la ciudad y sus habitantes: el trabajo y la sociabilidad; la arquitectura y las obras públicas y privadas; la presencia sindical y religiosa; el movimiento social, la economía industrial, su auge y decadencia, el comercio local y la economía doméstica; el empleo, los roles y la socialización.

En lo fundamental, a través de la actividad minera, en Lota se desarrolla una cultura del trabajo que penetra todo los intersticios de la ciudad. Se constituye una clase social proletaria, con un sujeto particular con identidad laboral y de clase, con componentes ideológicos socialistas y sindicalistas, apoyado por periódicos y folletos doctrinarios, anclado en una actividad única. Este trabajo se realiza en la profundidad de la tierra, de manera submarina y con una extensión que puede medirse en kilómetros, por lo que el trabajo es realmente riesgoso y distinto, así la actividad es considerada "titánica, heroica y fabulosa" (Corvalán, 1992, p. 129). Los hombres, entregados con incertidumbre a las honduras de la tierra y la oscuridad y encomendados a sus convicciones religiosas, bajaban casi 500 metros en forma vertical en "jaulas" (ascensores) para ingresar al túnel, llegando a internarse más de 15 kilómetros en forma horizontal bajo el océano; de ahí que el trabajo diario - mezcla de fuerza física y habilidad-pareciese una eternidad y que los ojos se encontraran siempre bien abiertos, los oídos alertas ante cualquier derrumbe en las galerías y el olfato aguzado para reconocer la presencia del gas grisú o viento negro. El trabajo, en medio de un barro que nunca abandona, de piedras crujientes, en galerías cuya altura máxima de la oquedad no sobrepasaba 1,60 metro y donde siempre había que estar agachado, es lo que configura un cuerpo y una imagen de minero: manos y brazos robustos, dorso sudado, cara húmeda y con costras de carbón, pulmones repletos de gases tóxicos; imagen que ha quedado proyectada en el tiempo y permanece como impronta propia de aquel oficio. 


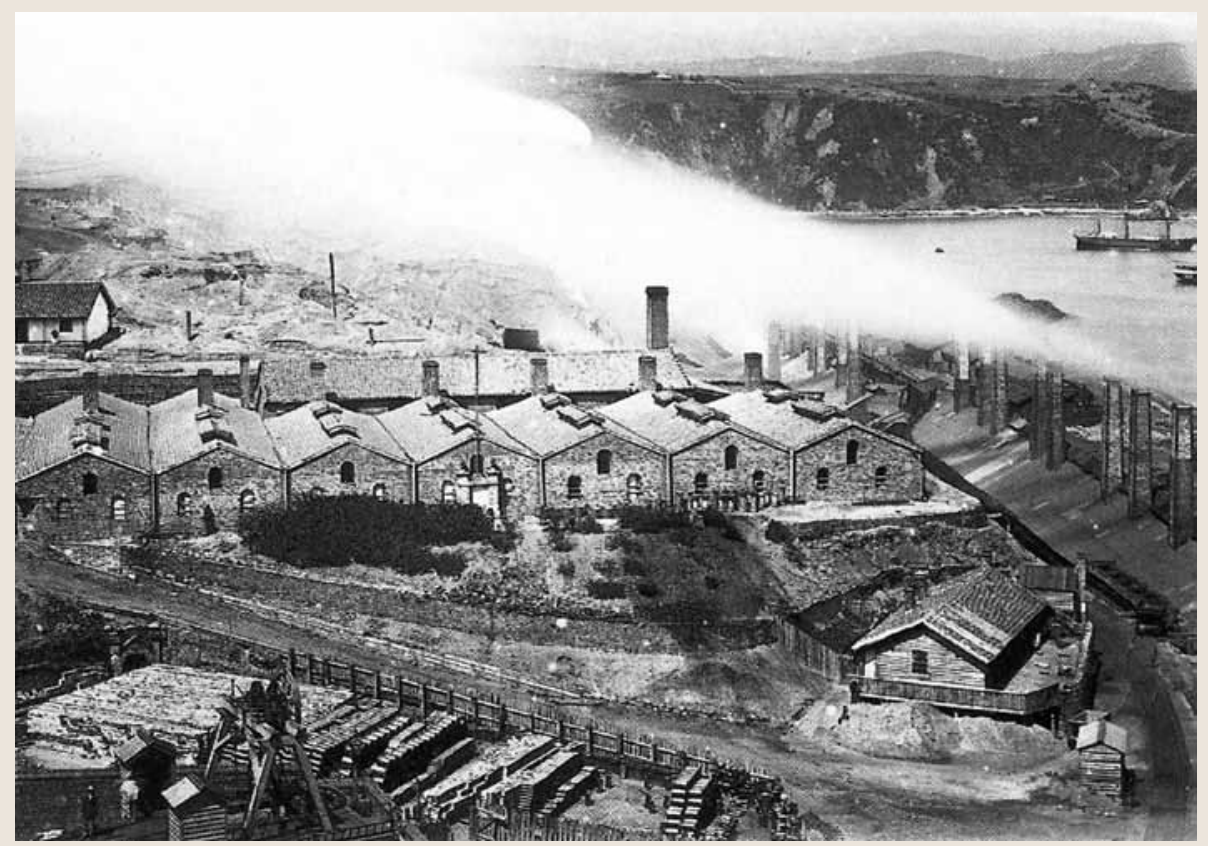

Vista del complejo industrial Lota Green, segunda mitad del siglo XIX. Fotografía de Guillermo E. Raby.

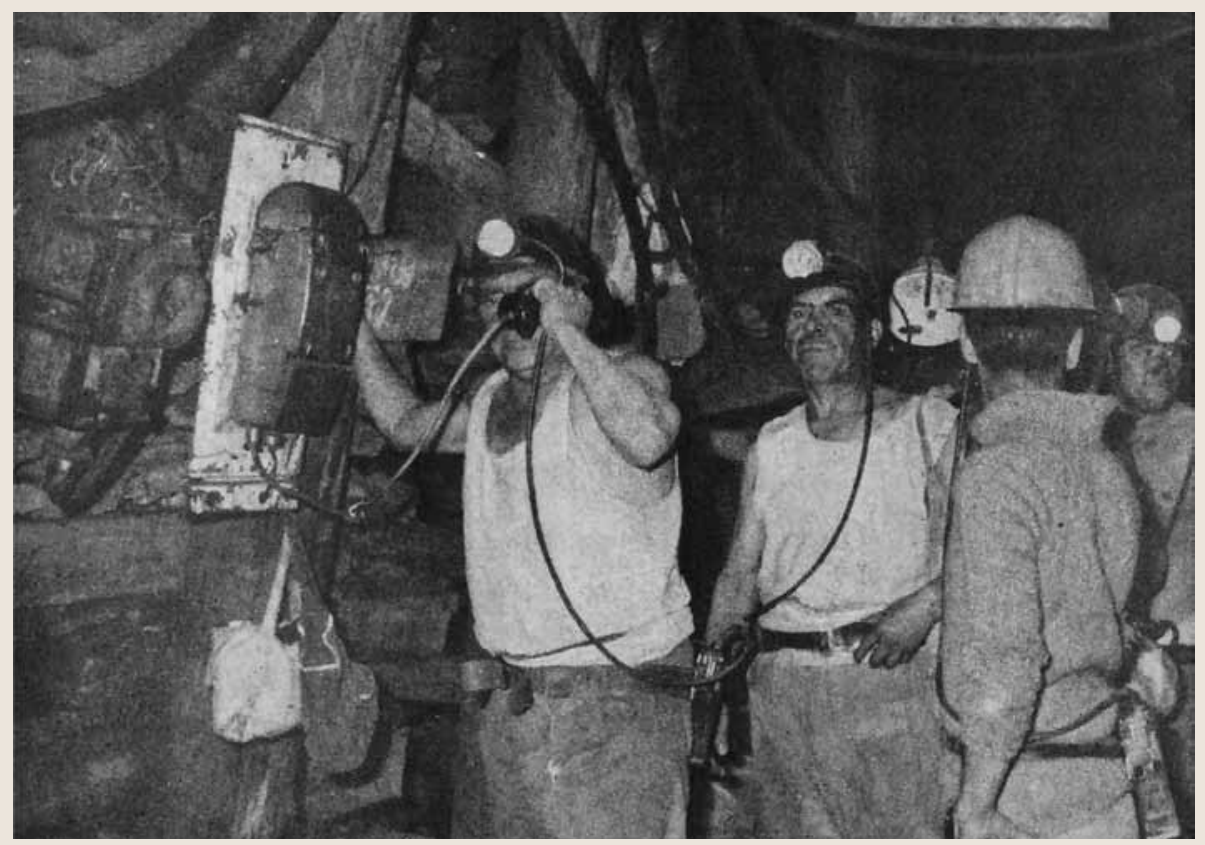

Trabajadores al interior de la mina. 
Desde una perspectiva etnográfica y etnológica, este modo de trabajar se constituye en una actividad tradicional, repetitiva, reconocida y sedimentada en el tiempo; la forma de trabajo con sus eternas rutinas y rituales, el riesgo al interior de la mina y el que no haya "en el mundo mayor silencio, a menos que lo interrumpa una gotera persistente, vil recordatorio de que el océano está encima" (Rivas, 2000, p. 6) es lo que hace que cada día se envejezca de manera acelerada y se muera un poco más en un trabajo que presenta históricamente pocas variaciones por los esfuerzos físicos comprometidos. Fue tan peligrosa en sus inicios, que pueden recordarse los llamados "penitentes blancos", quienes vestidos con una túnica blanca y mojada, entraban a la caverna antes que las cuadrillas de trabajadores, con un chonchón de llama prominente, sólo para quemar el gas (Alcalde, 1973, p. 41).

El proceso de trabajo define y estructura a través de generaciones la identidad de sus trabajadores y la identificación de la ciudad con el carbón al transformarse en potentes elementos de distinción frente a cualquier otra tradición minera. Con el trabajo en común y en estas condiciones de arrojo, "donde siempre se siente miedo y donde no todo está bajo control", se generan compromisos de lealtad que llegan a ser evidentes a través del tiempo; todo lo que aflora a la superficie es una memoria de lo que la mina esconde, de turnos sincronizados, de cuadrillas de trabajadores convertidas en confianzas y amistad, de acercamientos religiosos y políticos, de millones de horas hombre extrayendo carbón; de dedos que arañaron la riqueza, de infinitas cavilaciones que nadie podrá registrar, de las marcas en el cuerpo propio y en los ajenos, de los huesos resentidos. Sin embargo, como conjunto de sentimientos y prácticas “... en ese espacio cada hombre sabía exactamente lo que tenía que hacer y valoraba su trabajo, por lo cual obtenía dignamente su salario" (Vega, 2000, p. 12).

El la labor al interior de la mina genera una narrativa sobre el significado social del trabajo y su impacto en la ciudad con una apreciación profunda y subjetiva, así como una relación social y de dependencia económica que se constituye como una figura continua en el tiempo. Las luces y contraluces de Lota se estabilizan en estas relaciones. Todas estas imágenes e identidades son las que invisibilizan otras figuras económicas locales.

Aun cuando lo propio de la revolución industrial se encuentra asociado al inventar, sustituir y desarrollar, fomentando nuevas rutinas y hábitos (Hobsbawm, 2002), el desempeño del rol minero carbonífero -entendido como jerarquía, distribución especializada del trabajo y diferenciación social- se profesionaliza de manera superlativa en sus niveles inferiores, por- 


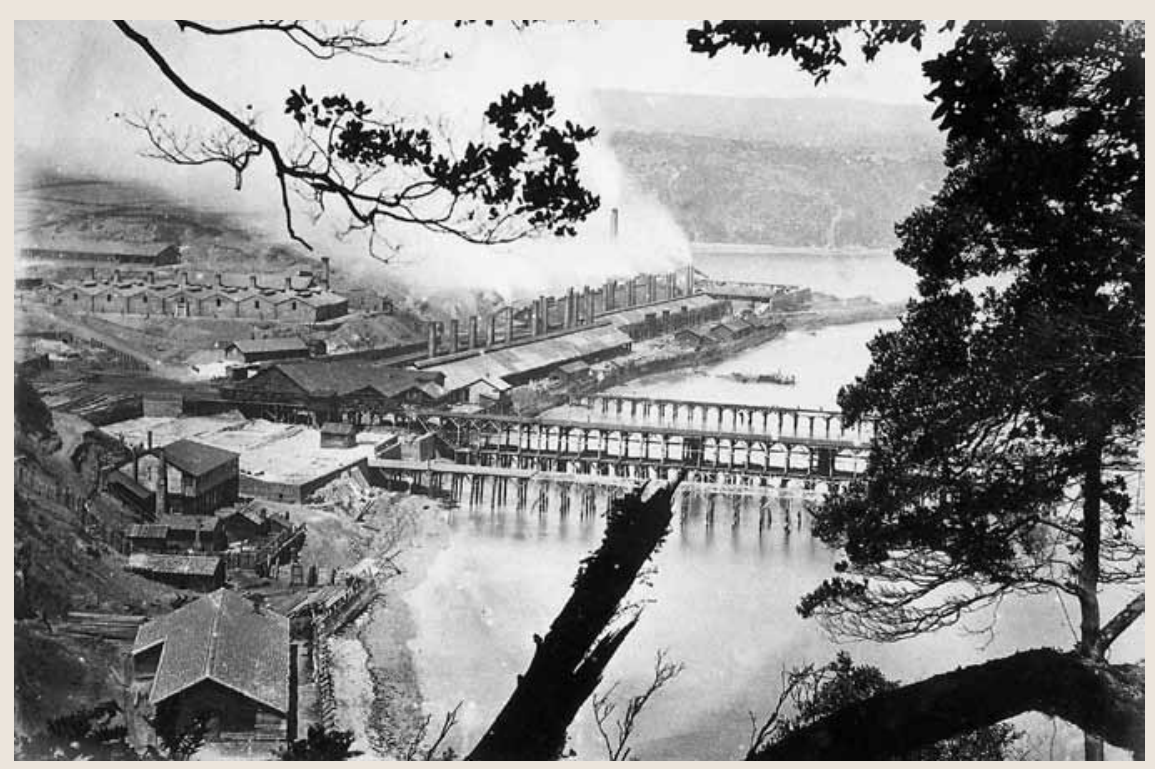

Vista del puerto y del complejo industrial de Lota, segunda mitad del siglo XIX. Fotografía de Guillermo E. Raby.

que lo rigidiza, debilitándolo ante el imperativo de enfrentar contingencias y visualizar actividades fuera de lo minero. Esto dificulta poder hacer un cambio adaptativo tanto frente a las oscilaciones del ciclo minero ${ }^{7}$ como a las situaciones de innovación técnica que puedan implementarse, ya que estas alteraciones no van de la mano de las consideraciones que se ubican en el plano ideológico y simbólico de las formas específicas de desempeño y autoimagen del rol. Esto significa que como cultura del trabajo hay un alto posicionamiento del rol y que no se puede innovar o cambiar en lo fundamental, sino más bien sólo respecto de lo tecnológico, porque el trabajo que otorga la identidad sustantiva, permanece casi invariable hasta el fin del ciclo minero en las postrimerías del siglo XX.

La conjugación de los particularismos del mundo del trabajo y el citadino es lo que decanta en un maridaje y dependencia recíproca, que moldea y potencia la imagen de la ciudad como "la ciudad del carbón", estableciendo la división funcional de la misma, entre Lota Alta, asociada a la constitución temprana de una company town que concentra los lugares habitacionales y

${ }^{7}$ Ciclo comprendido como el proceso de introducción del mineral en el mercado, ascenso en la demanda y la producción, madurez y estabilización de la producción y demanda, hasta la fase de declinación del producto. 
de servicios mineros, y Lota Baja, figura gestada al margen de la empresa, pero ligada a su complemento administrativo y comercial. Esto permite la sustentabilidad funcional de actividades burocráticas asociadas a la presencia del Estado y las iglesias en sus distintas confesiones y las relaciones comerciales ligadas a la feria y la pesca artesanal.

La mina estructura la ciudad de Lota y el repertorio de posibilidades sociales, culturales, económicas, sanitarias, educacionales y habitacionales de su población por generaciones. La deja a merced de ella y le permite desplegarse en toda su configuración socioespacial así como en su diferenciación ocupacional por actividades y entre trabajadores de la empresa y los subcontratados, por lo que la ciudad, en su estratificación se debe y construye desde la riqueza material y simbólica devenida de la mina. Por ello, todos los cambios en la industria y en la plantilla de trabajadores afectarán la fisonomía de la ciudad y de la zona.

El aprendizaje y la experiencia del trabajo minero se transforman en un modo de vida, en rituales, en formas de nombrar y registrar la experiencia dentro y fuera de la mina, en relaciones estables y permanentes tanto en los sindicatos como en la vecindad y en el intercambio diario en la ciudad, en la ocupación del espacio urbano, en el uso de los servicios, en los lugares de sociabilidad masculina como las cantinas, los prostíbulos y los de las prácticas deportivas ${ }^{8}$, en la especificación de los roles de género, las expectativas sobre la vida como proyecto vital, un cierto deber ser, ya que todo hijo de minero debía serlo también y sus hijas debían casarse con uno de éstos. En esta dinámica, a Lota Alta se anuda el caminar por las galerías de los pabellones con el hollín impregnado en las fachadas de cada vivienda, la ropa que flamea colgando de los tendederos, las chimeneas humeantes, el pan diario salido de los hornos que corresponde a un espacio de sociabilidad femenina. En términos simbólicos, corre siempre en paralelo y con fuerza la tragedia y el luto asociado al trabajo, el dolor de la pauperización, el conflicto, la esperanza por un mundo más justo y con más reconocimiento, el cual es representado por las organizaciones sindicales y políticas. El cuerpo exhausto buscó por décadas dejar atrás las lámparas de aceite, la ropa confeccionada con sacos de harina, los cascos de cuero y ojotas usadas en vez de zapatos de seguridad, jornadas de ocho horas diarias, alcanzar una jubilación a los 25 años de trabajo; sin embargo, la fatalidad de la amputación

\footnotetext{
${ }^{8}$ En registros de campo se señala de manera coincidente que "los hombres se juntan para hacer deporte o para ir al bar a tomarse un trago, ellos van en las mañanas al sindicato o al club deportivo, por las tardes ven televisión o se paran en alguna esquina a conversar, por las tardes van a la iglesia o a la cantina a juntarse con otros amigos".
} 
de una extremidad por un derrumbe o un tiro mal ejecutado o la fractura de columna e invalidez total, también formaron parte de su sino trágico. La muerte, como elemento propio del riesgo del trabajo subterráneo, es un rasgo omnipresente en esta sociedad, tal como se expresa en su cementerio y en los recuerdos colectivos sobre accidentes al interior de la mina o hechos luctuosos.

A partir de lo señalado, es importante destacar dos situaciones diferentes, aunque corren históricamente de manera simultánea. Por un lado, se configura una cultura del trabajo con su rigidez de los roles dados por la experticia desarrollada y su símil, igualmente rígido, reproducido al interior de los ámbitos familiares y domésticos; y por otro, se presentan de manera permanente unos muy deficitarios indicadores sociales en salud, alimentación, educación, vivienda, recreación, salarios y jornales, los que son revelados tempranamente y en profundidad en el primer estudio sociológico sobre la condición de los mineros y sus familias (véase Di Tella et al., 1966).

Esta pionera investigación sociológica intitulada Huachipato et Lota, establece el sistema general de estratificación social, el comportamiento demográfico, la movilidad social y la situación de la clase obrera en ambos enclaves industriales (1966, p. 15). Allí se establecen cuestiones como la existencia de "callampas" y viviendas deficitarias, que el 80\% de los trabajadores no tiene instrucción escolar ${ }^{9}$ y que las estadísticas oficiales hablan de un nivel de mortalidad infantil de 210 x 1.000 nacidos vivos, los que morirían antes de un año (ibíd). Los datos son significativos, lo que le permite establecer al equipo de investigadores las grandes diferencias con los trabajadores del acero en Huachipato, quienes accederían a una inserción más tardía al trabajo, a otras condiciones laborales, de vida, al desarrollo de una conciencia distinta y a una autoimagen como trabajadores de "clase media", en contraste con la pobreza infinita de los trabajadores carboníferos.

Sobre estas condiciones generales que hablan de proletarización y del perfil de la pobreza, Luis Ortega (1992, p. 109) agrega como antecedente histórico que muchas veces el agua consumida por la población ya había sido empleada por un numeroso contingente de lavanderas o que se habían vertido basuras o aguas servidas sobre ellas, que podían observarse mataderos clandestinos, mala calidad de los alimentos, adulteración de la leche, el azúcar y el vino, o carne de perro vendida por oveja. Quizá, lo único luminoso, blanco y contrastante será el pan salido de los hornos comunitarios,

${ }^{9} \mathrm{El} 4 \%$ se encuentra sin instrucción, $43 \%$ tiene sólo entre $0-3$ años de escolaridad, $49 \%$ entre 4 y $6,2 \%$ con tres primeros años de estudios secundarios o técnicos y sólo un tercio en edad escolar no frecuenta la escuela. 
donde las mujeres transformaban los tres quintales de harina mensuales a los que accedían, en el alimento central de su dieta. José Román, en su documental Reportaje a Lota, de 1970, recorre la vida en la ciudad, testificando lo que hoy parece un Chile lejano: niños haciendo una fila interminable para recibir un plato de comida.

Todo lo anterior contrasta ostensiblemente con la información ilustradamente presentada por la Compañía Carbonífera e Industrial de Lota en su texto de balance Cien Años del Carbón de Lota, 1852-1952, donde se señala un contrapunto entre el antes y el ahora:

desde la penosa época en que no había más techo que el barracón improvisado hasta el hogar minero de hoy, confortable, con blanca cocina, risueño comedor y baño moderno; desde la época del minero que no sabía leer ni escribir hasta hoy, en que las escuelas modelos abren las ventanas del saber para todos; desde la época en que el trabajador empuñaba las herramientas con ceñudo impulso hasta hoy, en que labora con optimismo, seguro del porvenir propio y de los suyos, teniendo a su disposición todas las conquistas del progreso: cine, teatro, radio, vacaciones, plazas de juego, hermosos parques que invitan a la meditación y al ensueño, modernos hospitales y clínicas, piscinas, clubes, campos de deportes, mercados, restaurantes, salario justo y seguridad social del modelo (Galleguillos, 1952, p. 18).

A pesar de esta lectura dual y antagónica sobre las condiciones de vida, concentración de población y de disciplinamiento laboral, en este enclave minero monoproductor se favorecía la forja de un mundo y un paisaje cultural masculino, con cantinas, burdeles, peleas de gallo, billares y carreras a la chilena, mostrando la ciudad una cara de importante diversión y esparcimiento, en paralelo con los indicadores sociales anteriormente señalados y con registros de historia oral, donde el recuerdo del hambre aparece como una figura central. Lo femenino, desde la familia minera y la agrupación arquitectónica que implica la zona residencial de Lota Alta, correspondiente a la company town, aparece minimizado desde lo masculino, ya que no existe en el imaginario de un mundo fálico, como el de la minería del carbón, otra posibilidad para las mujeres más que el mundo doméstico, el que constituye, como se indica en los registros de historia oral, una pauta de socialización y una línea demarcatoria de lo que será el universo de sus posibilidades e "invisibilización por 150 años", hasta el fin de la actividad minera ${ }^{10}$. Sin

\footnotetext{
${ }^{10}$ La idea de invisibilización constituye una constante dentro de los registros de historia oral y las entrevistas etnográficas desarrolladas durante los años 2009 y 2010.
} 
embargo, el protagonismo de la mujer son mostrados en diferentes investigaciones históricas desde los momentos iniciales del desarrollo de la ciudad (Figueroa, 2009) y de manera testimonial en el presente: "fuimos decisivas en las huelgas, ya que el primer día, a los maridos les atrasábamos el reloj o en la intimidad les decíamos quédate un rato más o les escondíamos los zapatos, para que así no llegaran al turno".

Categóricamente, así como Lota es la primera ciudad industrial, también con ella -como se desprende del trabajo de Di Tella y equipo-adviene y se estabiliza la pobreza urbana, situación que permanecerá como un sino, como una marca de identidad propia del lotino y de su ciudad hasta los tiempos actuales. Estas situaciones han permitido que toda lucha contra esta escena de pobreza lo sea también por la superación de las condiciones laborales, al igual que toda lucha por la mejora salarial y de seguridad en la explotación del carbón lo sea también por la calidad de vida en el espacio urbano. La externalización narrativa de la condición precaria de trabajo bajo el océano, esa que en el relato de Baldomero Lillo (2009) se encuentra más cerca del infierno que del paraíso, es también causa de esfuerzos organizativos, procesos políticos y de cambios contractuales y económicos, tendientes a corregir lo que fueron esclavizantes jornadas de peligro e inseguridad, el pago a través de fichas o sólo en cuatro ocasiones en el año.

\section{IDENTIDAD E IMAGINARIO EN LA LOTA MINERA}

Desde una mirada diacrónica, dos cuestiones aparecen y destacan para estructurar la identidad y el imaginario que subyace a este mundo del carbón: la singularidad del trabajo en la interioridad de la mina y la organización social en el exterior de ésta. Sin este doble reconocimiento, Lota es impensable, porque como acontece en toda comunidad especializada, se llega al lugar en el que habitamos todos: el lenguaje, representado en un habla particular, no sólo como expresión de una subjetividad, sino como posición social en un espacio y un tiempo. En las narraciones de sus ex trabajadores y sus familias sobre la vida individual y colectiva, de la ciudad y sus transformaciones, del ir y venir genealógico entre el antes y el ahora al que conduce la memoria oral, los lleva siempre a una narración épica, heroica y casi mítica de interpenetración de mina y ciudad, de presunción de mejores posibilidades y de esperanza, de una sociedad minera que crea condiciones para la utopía y que cree firmemente en ella.

El aire mítico que sustentaría el imaginario se encuentra dentro de la 
mina y fuera de ella; está en el trabajo, en la movilización social y en el sentido de justicia social. Así, se nos revelan al menos en tres grandes conflictos huelguísticos que muestran la dualidad mina-ciudad, los que nos dan cuenta de la constitución de un sujeto colectivo que respalda la configuración del enclave lotino y de una particular expectativa sobre la vida, en un claro interés por torcerle la mano a las dificultades para hacer frente al destino: la "huelga grande" o "huelga larga", de 1920, que interpelaba por la reducción de la jornada de trabajo a 8 horas, el aumento del jornal y el fin de la policía empresarial; la huelga de 1946, demandando mejores condiciones de trabajo y salariales, ocurrida en el Gobierno de Gabriel González Videla, quien militariza la zona y traslada a trabajadores a otras regiones e inicia un proceso contra 99 dirigentes sindicales y políticos, incluyendo al alcalde de la ciudad; más tarde, en el Gobierno de Jorge Alessandri Rodríguez, un conflicto donde el gobierno y la empresa habrían bloqueado el ingreso de alimentos a la ciudad para contener la manifestación, quedando la huelga postergada indefinidamente luego del gran terremoto de mayo de 1960.

Se pueden encontrar en términos históricos otros muchos conflictos antes y después de estas fechas, inclusive en vísperas del cierre de faenas, como los "once días bajo tierra" en 1997 después del despido de 756 trabajadores por la carbonífera Schwager (Vega, 2000); pero, en su conjunto, con la sumatoria de todos los episodios se va configurando la huella mimética de la fuerza y organización minera, la expectativa y la esperanza que direccionan la vida, hasta constituir un poderoso sujeto colectivo que lo instala en el imaginario social del país, tal como lo hicieron los obreros del salitre en el norte grande.

La lucha y movilización sistemática por mejorar las condiciones de trabajo y de vida son los elementos claves que forjan el heroísmo que sostiene la imagen más permanente de la comunidad y su identidad. Esta impronta le permite al movimiento social situarse en el tiempo con relación al pasado y al futuro, proclamando una pertenencia y un lugar en la historia, dentro de una sociedad que por décadas se presentó como una realidad invariable y continua. Siempre destacan los mismos términos para configurar la identidad filial de Lota, un contrapunto entre un presente alineado con la pobreza y la injusticia social y la esperanza de un mundo mejor. Es por esto que cuando se explora la memoria colectiva en la actualidad, ésta mantiene vigente la idea de la huelga, la asamblea, la organización, el sindicato, el partido, el orden, la alianza, el bien común, la solidaridad y la lucha; todo esto en referencia al pasado como al fortalecimiento de la autoestima. Así, se desarrolla una cultura del trabajo que vive el conflicto y busca formas 
de resolución total o parcial del mismo y, en esa misma medida, esclarece y augura un cierto porvenir para vivir la ciudad y en la ciudad.

El paroxismo de esta esperanza está en la chilenización y nacionalización de la industria del carbón y en el advenimiento del Gobierno de Salvador Allende en el año 1970, donde muchos creyeron que la vida les daba una segunda oportunidad y que la utopía era posible, porque por primera vez los mineros y los ciudadanos se sintieron dueños de un sueño, de sus propias vidas y su destino. En este sentido, para contextualizar, baste recordar el testimonio registrado por Alfonso Alcalde a un minero en el año 1973, en pleno proceso de nacionalización de la industria: "yo no me puedo olvidar de unas palabras de Recabarren cuando dijo: que nosotros tarde o temprano teníamos que llegar al poder, y lo que dijo Recabarren efectivamente resultó cierto" (Alcalde, 1973, p. 24) ${ }^{11}$.

Sin embargo, en una mirada de largo plazo, a pesar de las movilizaciones permanentes y las expectativas crecientes propias del proceso que les permite convertirse en sujetos, serán siempre fenómenos extralocales los que marcarán el sino trágico del centro productivo y la sociedad, los cuales irán erosionando y rompiendo la coherencia entre el habitante y su hacer, entre el habitante y su memoria, entre la ciudad y la esperanza, entre la ciudad y el proyecto vital, tanto en lo material como en lo espiritual.

Las vicisitudes de la actividad carbonífera y sus claves son extremadamente potentes para afianzar un doble imaginario: el de la riqueza sin límites de la familia Cousiño, del hombre visionario fundacional que está detrás de la ciudad, la vivienda, el Parque, el hospital, la escuela, el trabajo y el desarrollo de Chile; y el del imaginario colectivo del obrero y sus condiciones de vida, retratado por Baldomero Lillo. Perspectivas que nos permiten hablar en términos duales tanto del proceso de acumulación de capital y generación de riqueza como del surgimiento de un contingente de proletarios en una urbe que nace y se desarrolla con una incuestionable dependencia de la explotación minera y de empresas asociadas.

La proletarización de lo minero tiende a esencializar y primordializar los rasgos sociales y culturales de los habitantes en relación a la ciudad y el mundo del trabajo carbonífero, enfatizando los aspectos subjetivos y de personalidad que permiten una gran identificación mediante las relaciones de cercanía, gestadas inicialmente en el subsuelo y en los sistemas de turno A, B y C, con jornadas de 7 a 14, de 14 a 23 y de 23 a 7 horas, con cuadrillas

\footnotetext{
${ }^{11}$ Luis Emilio Recabarren va a la zona carbonífera en 1919.
} 
estables que forman equipos, constituidas por unos 1.000 trabajadores en cada uno de éstos a comienzos de los años 70, donde participaban los de producción que extraían el mineral, los de preparación del frente de avanzada que habilitaban las condiciones de extracción y los de preparaciones generales que abrían las galerías, compuestos por técnicos en minas, ingenieros, mayordomos y disparadores; todo lo cual generaba una confianza y lealtad básica ya que "adentro, todo se olvida, porque somos todos iguales". Estas relaciones sociales subterráneas eran proyectadas en la superficie al sindicato, los clubes deportivos, la religión, el territorio, la familia y el parentesco.

Como observaremos, la vulnerabilidad de los enclaves monoproductivos de recursos primarios es especialmente sensible a los cambios, ya que sus posibilidades dependerán de la estructura de la demanda, de los precios, de la eficiencia productiva, los costes de producción, de la competencia y de la ley del mineral.

\section{CIERRE DE LAS MINAS Y DECLINACIÓN DE LA CIUDAD}

El debilitamiento productivo de la industria del carbón comienza en la década del 50 del siglo pasado, cuando se modifica la matriz energética del país con la introducción del petróleo y la hidroelectricidad, desplazando al carbón como primera fuente energética. Sin embargo, el fin de la actividad minera institucionalizada sólo se concreta el 17 de abril de 1997 con un lacerante anuncio por parte del presidente de ENACAR Jaime Tohá González: el cierre constituye la "única opción responsable".

La vulnerable condición monoproductora de Lota se anuncia por décadas. La declinación de la ciudad la hace ver siempre como una suerte de enferma crónica que, aunque con intermitencias positivas, se agota cada día un poco más. Las navieras, el ferrocarril y las fundiciones, que eran las grandes consumidoras del mineral, ya no requerían de esta fuente energética; las industrias asociadas de ladrillos y vidrios dejan de operar. Con ello, se instala un claro mensaje: no se necesitan tantos trabajadores en las faenas. Luego se sumarán otras consideraciones como el aumento de los costes de producción (internación más extensa bajo el mar, el refuerzo de galerías, valores de la madera para el envigado) que encarecerán los procesos y harán muy poco competitiva la extracción del carbón frente a otras fuentes energéticas y al mismo carbón extranjero.

Todos los antecedentes, al menos desde la segunda década del siglo pa- 


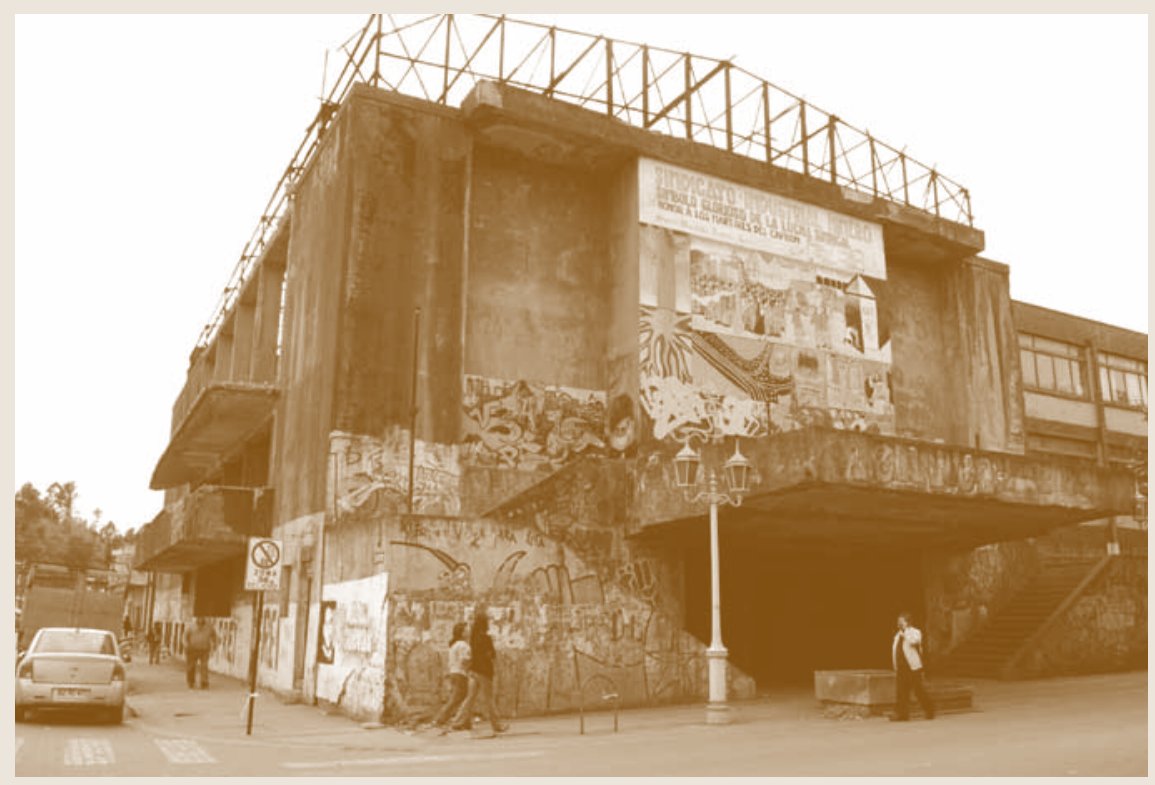

Teatro y Sindicato Obrero, nunca terminado, ubicado frente a la plaza principal de Lota. Fotografía de los autores.

sado, indican que no es posible reconfigurar la estructura interna del proceso productivo (condiciones tecnológicas, financieras, laborales y administrativas), porque es la obsolescencia general de las condiciones bajo las que opera la explotación la que entra en crisis y lo que le condena a desaparecer, ya que no hay posibilidad de mejoramiento continuo del proceso.

Entonces, en esta trayectoria de declinación que corrió de la mano de la construcción del espacio local, pueden encontrarse los elementos de continuidad y discontinuidad en la relación entre lo económico y lo social, la fuerza de la esperanza y la profundidad de la desesperanza, las apuestas para vivir en la ciudad y la incapacidad o negligencia del Estado para prever escenarios y generar alternativas, así como la capacidad de negociación de quienes han sido los actores históricos. También será el cierre de las minas y el fin de la actividad carbonífera local, lo que en lo fundamental obligará a revisar el contenido de la propia vida de quienes por generaciones son parte del mundo carbonífero a través de los espacios que contienen la memoria y de los particularismos de la ciudad y sus gentes; porque la memoria se funda y se expresa en un sistema de imágenes y relaciones que también entran en un proceso de reconfiguración socioespacial y temporal, así como los lugares masculinos y femeninos sostenidos tradicionalmente, ya que los 
rituales asociados a sus trayectorias y sus sistemas de referencia deben ser reestructurados.

Como ocurre con toda tradición que declina, esta experiencia intergeneracional de ser minero se confronta hoy con la peor de las situaciones: "la de mirarse las manos y saber que ya no sirven para nada, la de mirar el reloj y saber que la hora que viene será igual a esta que está, la de pensar en el día de mañana, y saber que será tan vacío como el de hoy" (Saramago, 2008, pp. 348-349). ¿Qué hacer con la propia vida? ¿Qué hacer con la ciudad? ¿Hacia dónde mirar? El cierre de las minas de manera indeclinable ubica a la población de cara a la incertidumbre y a nuevas angustias, esta vez definitivamente en el subsole.

\section{LAS RECONVERSIONES: UNA POSIBILIDAD TRUNCA}

Conceptualmente la necesidad de reconversión industrial es un fenómeno muy propio de la constatación del desigual desarrollo tecnológico entre industrias y países, de la baja o nula integración comercial de un subsector de la economía nacional y de la poca competitividad que tiene el sistema, el recurso o el producto en el mercado. La necesidad de reconversión laboral es siempre un procedimiento a través del cual se pretende reincorporar laboralmente a los trabajadores, los que teniendo habilidades específicas y validadas, como las observadas en el trabajo en la profundidad de la mina desde el siglo XIX, no tienen posibilidades de ejercerlas por razones externas a ellos y porque carecen de un repertorio de alternativas para permanecer en el mercado de trabajo con dichas habilidades ocupacionales.

De este modo, frente a un subsector laboral y económico que debe reconfigurarse, se trata básicamente de crear empleos. Analíticamente, por un lado, encontramos como posibilidad la autonomía e independencia de los sujetos en la búsqueda de un camino para reconvertirse y, por el otro, el Estado como agente interventor, facilitador y direccionador de opciones laborales. Así, la decisión indeclinable del cierre de las minas ubica formalmente como escenario y cuestión estratégica dos opciones: la generación eficiente de alternativas en el nivel individual y estatal o el riesgo de una aplicación negligente de procedimientos en la reestructuración interna del sector por parte del Estado como propietario de las minas.

Las opciones de Lota que fueron definidas como áreas de prioridad para su sustentabilidad como ciudad y como reconversión laboral para los cesados de la minería, son: madera, microempresa, pesca y turismo. Se pen- 
só en una planta procesadora de algas, en un plan de obras públicas, en parque y condominio industrial con unas 15 industrias medianas para dar trabajo a 300 personas. Sin embargo, no resultó el proceso de recalificación y readecuación de las personas. No hubo interés en ser peluqueros, electricistas, soldadores y manipuladores de alimentos; no se desarrollaron otras experticias a través de nuevos conocimientos y habilidades tanto en la recapacitación como en la adaptación personal, mostrando, además, que a mayor edad de los ex trabajadores, las opciones fueron más restrictivas y con menor recepción, lo que hace que para los desafiliados, la vejez se viva también con mayor dramatismo.

Podemos afirmar que es de una complejidad distinta plantearse el proceso de reconversión laboral del minero como una cuestión formal y técnica, a plantearlo como una reconversión cultural, una reescritura biográfica y de modos de vida, incluso lingüísticos, de estos actores sociales. Antropológicamente hablando, esto implica mirar y considerar la ciudad y sus habitantes desde aspectos existenciales, anímicos y temporales, ya descritos en las páginas precedentes, los que atañen a la construcción de la subjetividad y a un repertorio de referencias históricas ligadas a sus propias leyendas y mitos, a la construcción de su imagen y autoestima.

Con el cierre de las minas de carbón, no sólo se pierde el trabajo que se domina y respecto del que se es experto, sino también la relación con el grupo de pares y todos los espacios comunes compartidos; se pierde el protagonismo, la visibilidad y así mismo el poder patriarcal. Se fractura la imagen colectiva, se resquebraja la vida privada, se producen "importantes rupturas matrimoniales, procesos de búsqueda de trabajo en el norte sin retorno, alcoholismo y suicidios"; Lota se transforma en ciudad dormitorio: "se sale de noche [madrugada] y se llega de noche, ya no se sabe qué pasa en la ciudad".

El trabajo en las minas fue precario y permaneció precario. Siempre primó la destreza física más que el trabajo técnico. Por ello, puede entenderse que el proceso de reinserción laboral después de la minería haya sido en extremo difícil, ya que no hay muchos márgenes para la reinvención cuando lo físico prima por sobre otras habilidades; son escasos los éxitos de trabajadores que lograron un proceso de incorporación a otras actividades. Otro factor destacable es que la experticia de la minería en términos de la rigidez que implicó es poco compatible con otras actividades regionales como la pesca y el trabajo forestal. Esta misma situación es la que se ha observado para el mundo salitrero, una vez que cambian los formatos de explotación del caliche y desaparece el sistema de protección tradicional, otorgado por 
las company town, desaparecen también los trabajos de baja calificación (Rodríguez y Miranda, 2010). Sobre este punto, De Dinechin agrega una observación importante: "La industria chilena es cada vez menos consumidora de empleos poco calificados y cuando lo es, ella los reserva a los jóvenes con vistas a capacitarlos" (2001, p. 79).

Con el fin de la actividad carbonífera local, los procesos de jubilación se hicieron recurrentes y las actividades laborales esporádicas y sin contrato constituyeron algunas fuentes de ingresos, aunque la gran mayoría ha vivido de las pensiones. Mirado el proceso con 10 ó 15 años de distancia, ex trabajadores narran sus procesos de reinserción como de escaso o nulo éxito, de fracaso en sus emprendimientos como taxistas, microempresarios de la locomoción colectiva, contratistas para empresas forestales o de desarrollos como mueblistas y comerciantes minoristas. Otra dificultad, escasamente considerada para un nuevo trabajo y reemprendimiento en superficie, estuvo asociada a los problemas de salud de los ex trabajadores, ya que de manera coincidente destacan enfermedades profesionales que hacen imposible la reinserción: várices, problemas a la columna, silicosis y artrosis en las rodillas.

El no encuentro o la no generación de una alternativa efectiva y eficiente de reemplazo al lugar ocupado por el mundo del carbón, es decir, de lo que fue una cultura del carbón, convierte a la ciudad en un lugar subvencionado artificialmente. Gran parte la sociedad ligada directa e indirectamente con la minería son personas subvencionadas, lo que instala una forma particular de envejecer sin lugar dentro de la comunidad, generando además un delta generacional imposible de compatibilizar. Esta subvención obligada, gestada desde distintos planes y programas del Estado, es la que hace posible que aún subsista también la parte no minera de Lota: las actividades de servicios, el pequeño comercio detallista, la pesca artesanal y la feria. El salario indirecto se constituye en factor central a la hora de pensar Lota después del fin de la actividad carbonífera, ya que hay ausencia de trabajo productivo local, producto del fracaso absoluto del proceso de reconversión de la actividad minera. Esto último, tal como lo sostiene Philippe de Dinechin (2001), porque primero se cerró la mina y luego se pensó en qué hacer con su gente y la ciudad.

Hoy existe una heterogeneización de las prestaciones sociales, donde el salario indirecto básico, que siempre es compensatorio y complementario (educación, salud, ayudas del municipio), se pone en paralelo con las jubilaciones anticipadas de los ex trabajadores. Por ejemplo, quienes jubilaron entre 1980-1982 lo hicieron con lo que los mineros llaman "la doble", que 
es equivalente a lo conseguido como parte de una negociación y que permitió acceder al doble de jubilación, pues les incrementaron en un cien por ciento el sueldo de trabajador activo. Por eso, encontramos hombres que jubilaron con poco más de 20 ó 25 años de trabajo en la mina, así encontramos jubilados a los 48 años de edad; además, existen leyes complementarias como las dictadas en 1992 que favorecieron las desvinculaciones y que permitieron el establecimiento de "puentes" -por 28 años- para que los mineros recibieran pensiones hasta cumplir la edad legal de jubilación; también hay una gran cantidad de planes de empleo menores y subsidiados; estos últimos, en una ciudad que cuenta con menos de 50.000 habitantes, se han movido desde el año 1996-1997 a la actualidad en una cifra de casi 4.000 empleos de emergencia o proyectos pro empleos, con un piso de unos 165.000 pesos mensuales ${ }^{12}$.

Este tipo de empleo "constituye un daño a la comuna" -nos dicen coincidentemente autoridades municipales, pastores y dirigentes sociales- ya que se perdió toda disciplina laboral. La política de subsidios fomentada de manera creciente en la última década, y de acuerdo a cuestiones históricas como la experiencia organizativa sindical, ha instalado una reivindicación por conseguir más subsidios en desmedro de una reivindicación por trabajo productivo que pudiese estar asociado a la instalación de un parque industrial que genere empleos formales. Con reiteración se insiste en que las familias "una semana piden que les arreglen la casa y a la semana siguiente piden una canasta familiar"; bajo esta fórmula "no se manifiesta [entre los lotinos] una condición propositiva que avance en sacar una comuna adelante". La estabilización del subsidio como política paliativa y compensatoria frente a la ausencia de empleos efectivos ha generado un "acostumbramiento a pedir y a no hacer", y de paso, a no producir. Señalan ex trabajadores que "fueron muchos los compromisos incumplidos al protocolo... Entonces están esperando... pero, Lota está llena de proyectos pro empleo porque no hay otra cosa que hacer"; es una espera de manos en los bolsillos, detenida en las esquinas de la ciudad, sin rumbo, en silencio, presa en un interregno, sin futuro (Medina, 2010) ${ }^{13}$.

Con un ayer con carbón y un presente sin trabajo minero se rompe el vínculo indisoluble con la actividad que prefigura la identidad, especial-

${ }^{12}$ Sólo la Casa de la Mujer llegó a administrar unos 400 empleos.

13 "Lota es un lugar barato para vivir", ya que basta con los subsidios; "nadie se mueve", ya que ir a buscar trabajo a otro lugar significa mayor esfuerzo y dinero en locomoción, por ejemplo, ir a trabajar a Coronel o Concepción. También, como corolario y elemento erosionador de la comunidad, existe la creencia de que como "antiguos obreros del carbón deben ser ayudados". 


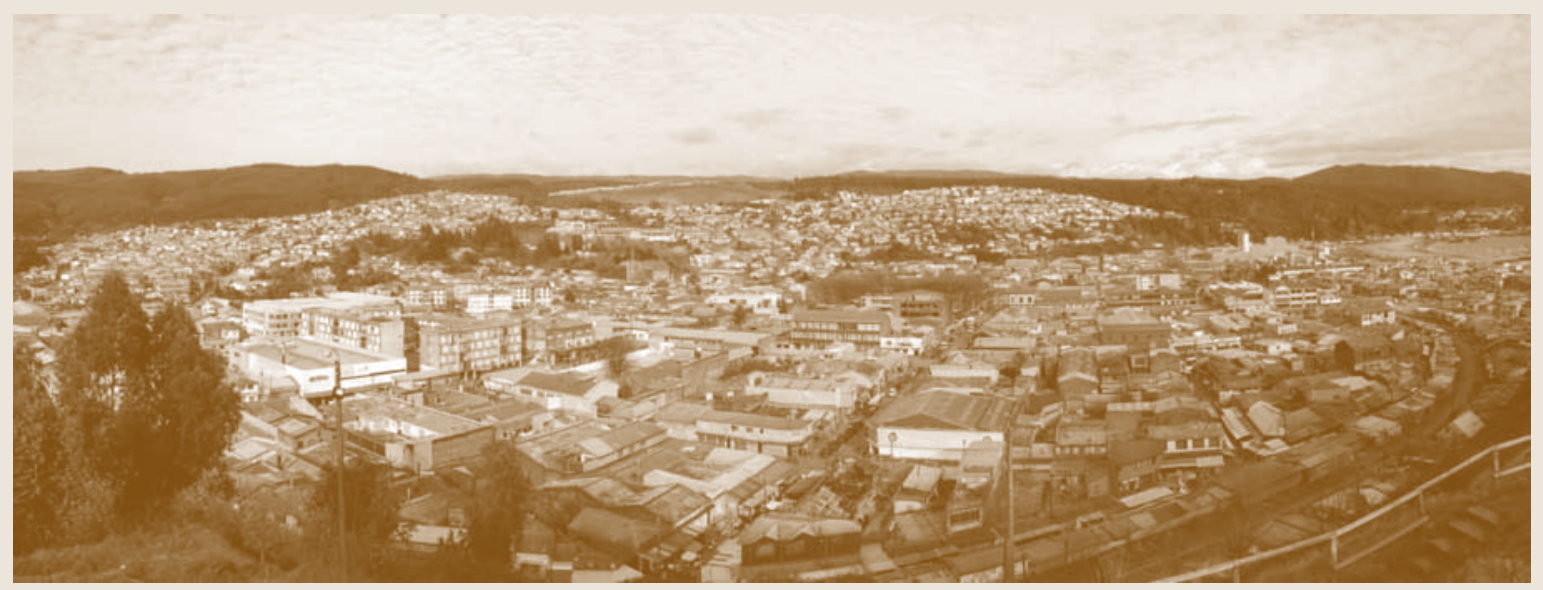

Vista panorámica actual de Lota Bajo. Fotografía de los autores.

mente en lo que corresponde a la situación contractual (existencial) con la naturaleza, que habla de un pacto productivo y laboral, que es el de la imagen de la mina como vientre. Esta disolución se representa también en los volúmenes deteriorados de la arquitectura de la ciudad, que hablan de la actividad industrial detenida y de los servicios asociados y complementarios que perdieron su función, quizá como metáfora de lo que acontece en la vida. De modo que, enfrentados los sujetos a lo nuevo, se produce una relocalización temporal en el imaginario tanto de las cuestiones materiales como simbólicas, ya que no hay construcción de la esperanza con los recursos y capacidades locales, ya que Lota no depende de sí misma.

Entre algunas de las preguntas que afloran, es si es posible que les paguen significativamente más a los ex trabajadores del carbón en otro lugar distinto a Lota, cuando no se tiene calificación. Frente a una respuesta negativa, la vida se conecta con la idea de la "espera" (Medina, 2010), entendida como condición de inmovilidad justificada desde el sentimiento permanente de reparación, porque el "Estado les debe" por su contribución al desarrollo del país ${ }^{14}$, ya que lo que "perdieron" paulatinamente fueron las seguridades básicas de empleos que fueron garantistas ${ }^{15}$.

El que la ciudad ya no produzca y no genere riqueza es lo que provoca su ingreso a un proceso de declinación. La ruina material tiene como correlato

14 "El país está en deuda con nosotros. Deberían poner una universidad en Lota".

${ }^{15}$ A los trabajadores como salario indirecto se les compensó con casa, cuentas de luz y agua, alimentos subsidiados y carbón como combustible, por lo que también sienten que el Estado debe contribuir a la reparación de esa pérdida. 
a la gente empobrecida. Por ello, cabe preguntarse: ¿Qué se puede controlar de la propia vida dentro de una ciudad que hasta ahora se presenta como no sustentable? Para la reconversión subjetiva aparece la leyenda como elemento conspirador y de memoria larga: "Cuando uno va a buscar trabajo afuera, Lota nos juega en contra. Lota o lotino es sinónimo de ser comunista, conflictivo; entonces, hay que cambiar la dirección de residencia... nos dicen que son buenos los antecedentes, pero que podemos ser conflictivos". Ahí aflora el recuerdo de la organización y movilización con toda nitidez en su dimensión teleológica.

Conforme a la edad, se instala un diferencial en términos de acceso al saber, a la información y a la apertura, lo que se traduce en un horizonte desigual en términos fácticos para realizar emprendimientos que se abran a otros repertorios de posibilidades laborales. La mina, para los más jóvenes, es sólo un elemento referencial, por lo que su vida está definitivamente en otra parte; no sólo se mira con más distancia el "ser minero", sino que hay más interés por explorar fuera de ese referente; en cambio, este horizonte es más restringido conforme se tiene más edad. Así, se vuelve muy claro lo que sostiene Manuel Antonio Baeza en cuanto a que la innovación tecnológica se desprende "brutalmente de los capitales acumulados de saberes anteriores en sentido estricto y de la memoria social en sentido amplio" (2008, p. 130), y éste es uno de esos casos.

El devenir de lo sucedido en Lota con los trabajadores mineros, más allá de las omisiones y falta de previsión, refuerza la idea de que no se trata de un problema técnico productivo. Es también un problema existencial, cultural y simbólico que atañe a la identidad y a una tradición.

\section{SABER HACER Y SABER USAR}

Mirado el cierre de la explotación de las minas sistémicamente, es factible observar que cuando nos referimos a lo no técnico del proceso de reconversión, aparecen un saber hacer, que corresponde a la experticia relacionada con la producción, una biografía, y un saber usar, correspondiente a los servicios, infraestructura y formas de negociación, los cuales permanecen como los rasgos propios de la crisis (Rodríguez, 2010). En sentido estricto, se trata de dos modalidades de expresión de la experiencia, ligadas a la identidad y la tradición, las que en su amalgama permiten la construcción de su imagen, definen la condición histórica de Lota y también la rigidez de los procesos rólicos adquiridos a través de generaciones; se trata de una ru- 
tina y unas prácticas asociadas al trabajo y de un sujeto que históricamente interlocutaba con un "patrón" y que poseía una particularidad única en sus saberes, específicamente en su hacer y usar.

$\mathrm{Al}$ romper el hombre de manera unilateral el pacto con la naturaleza (porque el carbón sigue existiendo), la ciudad habilitada con sus instalaciones para el trabajo productivo comienza a verse fantasmagórica, debilitada, vacía, deteriorada; se torna en un lugar de ausencias, en cuanto van transformándose en ruinas los vestigios de la arquitectura industrial, desapareciendo la inversión social tanto pública como privada. La ciudad de Lota representa al pasado y es el pasado, porque apela a la representación de un hacer que ya no existe, en la que ya están de manera fosilizada las presencias del carbón. Las relaciones pueden ser representadas en otros frentes, pero no en su pacto, lo que queda indicado tanto en la ruina como en aquellas instituciones que hoy tienen la categoría de imaginarias ${ }^{16}$.

El pacto roto no corresponde a un recurso que se fue. El recurso "está, hay miles de toneladas, millones esperando". La ruptura es entre mineros y empresa, entre mineros y Estado, pero al salir un actor del escenario, se rompe el vínculo con la naturaleza, la capacidad de negociación y la certidumbre con la que se construía la esperanza y se sostenía el imaginario. De este modo, la ciudad deja de ser el centro de la inversión y de los usos de un tipo de saber específico. Lo que encontramos es que hay saberes sin haceres, porque la cualidad del hacer histórico no existe. El carbón como fuente de producción de riqueza ya no está como posibilidad laboral, desapareció para siempre. Esta condición es distinta a la de la cesantía, porque en ésta sólo se está "de para", transitoriamente sin trabajo, pero la actividad conocida no desaparece.

De acuerdo a la trayectoria existencial, laboral y política de los mineros, éstos no están acostumbrados a depender de sí mismos, a poseer una autonomía social básica, ya que permanentemente vivieron en condición de asalariados. Es por esto que el proceso de autonomía que instaló el programa de reconversión no tuvo viabilidad ni constituyó una ventaja, ya que los procesos aculturativos vinculados al ser y al hacer no tienen sincronía con los procesos tecnocráticos y tecnológicos aculturativos planificados. Puede

\footnotetext{
${ }^{16}$ Nos referimos a que en Lota se encuentran muchas sedes sindicales, que corresponden a espacios importantes y residuales del carbón. Se trata de organizaciones que mantienen vínculos en torno a aquello desaparecido, que operan como tejido de amistad, refugio de recuerdos. Sin embargo, no puede haber sindicato cuando no se tiene empleador. Quizá, lo más extremo de esta situación sea un sindicato de ex trabajadores de la película Subterra.
} 
sostenerse entonces, que se trata más bien de un problema que ya no se solucionó y que la apuesta final parece haber sido dejar que el tiempo haga su labor con los más dañados.

La reconversión tiene el problema estructural de que el cierre de la mina se impone antes de realizar o desarrollar una mirada prospectiva de largo plazo. Claramente, su vecina Coronel fue una ciudad más proactiva en su reconversión, desde la perspectiva de su gente y sus autoridades, logrando desarrollar un parque industrial; Lota, en cambio, apostó durante largo tiempo al no cierre de la mina, cuando todo indicaba que era inviable mantener su apertura. Esto finalmente restó adhesión de la población a cualquier proyecto, transformando la ciudad y la vida económica de su población hacia un marco de subsidios permanentes como los que se han detallado más arriba (De Dinechin, 2001, p. 74).

Recogiendo lo anterior, la ciudad de Lota pareciera presentar una cierta paradoja y distorsión: es activa en la zona baja constituida comercialmente y representada, principalmente, por la feria libre que atiende los 365 días del año, pero no posee otra actividad económica significativa en ninguna otra zona. Sin embargo, esta observación no es atribuible a una actividad económica de gran impacto en el PIB regional, sino que refiere a una cuestión geográfica, ya que es una comuna casi $100 \%$ urbana y donde todo converge hacia el centro. Las actividades principales son el comercio con un 17 ó $18 \%$ y los servicios públicos con un 11 y $12 \%$, ya que no hay industrias productivas. La pesca artesanal sólo representa a un 5 o $6 \%$ de la población económicamente activa.

Lota, además, se ha quedado sin una población que opere de forma crítica, porque para un profesional no hay oportunidades como las ofrecidas por otras urbes mayores ${ }^{17}$. Lota, en términos históricos, no ha sido capaz de crear riqueza ni oportunidades para su gente. En esa misma medida podrá apreciarse cómo y por qué disminuye su población.

Con el cierre de la actividad extractiva se produce una modificación del deber ser histórico. La palabra la toman las iglesias y no los sindicatos ni los partidos políticos. Aunque no de manera exclusiva, el relato de la esperanza se deposita fundamentalmente en la religión. Quizá en esta perspectiva pueda entenderse que el $60 \%$ de población sea evangélica, según reconocen los pastores. Se fue el sindicato, el dirigente, la huelga, la lucha sindical, generando un gran vacío que es llenado por estas formas filiales

${ }^{17}$ El problema de la vivienda sigue siendo un problema crítico, lo que limita los deseos o intereses por el arraigo. Los profesionales no residen en Lota. 
y de acompañamiento. Ahora aparece el pastor, la presencia religiosa, la movilización por el paraíso religioso; hay una inversión de las categorías históricas, pasando de la esperanza social a la esperanza espiritual. En el templo la gente entiende la súplica y los feligreses pueden comprender y compartir el mismo sentido de la esperanza y la ilusión.

\section{LA CIUDAD SIN EL CARBÓN: LAS MARCAS DE LA DECLINACIÓN Y LA REFUNDACIÓN DE LOTA}

En la ciudad se observan en distinto estado de conservación construcciones que revelan la armonía y un cierto esplendor que ilumina el mito de su grandeza industrial del que, en contradicción con los antecedentes descritos, hacen gala sus antiguos y nostálgicos habitantes y defensores. Destacan su parque, la casa de quien fuera el médico de la familia Cousiño, la ruina del antiguo hospital de la Compañía, la mole de la cervecería (destruida completamente por el reciente terremoto de 2010), el muelle, la fábrica de refractarios, la maestranza, los extractores de aire que ventilaron los piques; inmuebles y elementos que constituyen un conjunto de instalaciones asociadas, coexistiendo con sus emblemáticos pabellones habitacionales, los cuales le otorgan el carácter e identidad peculiar a su arquitectura y condición urbana.

La ciudad, herida en lo que corresponde a los volúmenes de la arquitectura de la company town, en su actual estado, no resulta atractiva para las nuevas generaciones provenientes de familias de tradición minera. Dudan -como otras- de vivir en Lota, ya que no tienen perspectivas de desarrollo local por una falta básica: ausencia de trabajo. En Lota, "apenas" -nos informan desde el Municipio- se han construido unas 500 viviendas básicas durante los veinte años de gobiernos de la Concertación de Partidos por la Democracia, "lo que no resulta atractivo para alguien que con mucho esfuerzo se ha transformado en ingeniero o en un profesional". En la actualidad, como sino de continuidad descrita por Di Tella y equipo, existen 22 campamentos y muchas soluciones habitacionales pendientes, lo que revela demandas contenidas de vivienda y saneamiento básico dentro de una necesidad de construir al menos unas 1.000 viviendas de manera urgente ${ }^{18}$.

\footnotetext{
${ }^{18}$ La situación se ha agudizado con el terremoto de febrero de 2010, ya que existirían unas 2.800 nuevas medias aguas.
} 
Desde el gobierno local se propone conceptualmente la "Refundación de Lota". Se esboza la idea de la construcción de un parque industrial y el desarrollo de la industria del turismo sobre una base patrimonial histórica, carbonífera y gastronómica, en complemento con servicios de hotelería y centros de convenciones. Estos dos ejes serían las fuentes centrales de una propuesta de generación de nuevas oportunidades, de riqueza y elementos retentivos para la población más joven, ya que existe la idea instalada de que hay una generación que envejeció y no sólo por una cuestión de edad, como se ha indicado, sino porque ya no puede ser reenganchada al mundo del trabajo formal.

La idea refundacional de Lota se refrenda en la imagen casi delirante de algunos de sus habitantes: "Lota tiene todo para ser Mónaco". Diremos: la sentencia es la imagen de la belleza superlativa para quien no ha salido nunca del mundo gris de los árboles de humo que formó cada chimenea, del interior de la caverna donde no cabe una sola estrella y donde el sol siempre fue negro. Pero es también la imagen intuitiva para restituirle toda su dignidad a través de la conservación patrimonial.

La condición expansiva del formato de patrimonialización nos ubica en dos escenarios: primero, la presentación de un cierto deber para la localidad, lo cual es propio de las estrategias de desarrollo regional y local; y segundo, una alternativa para el desarrollo de las comunidades, cuestión especialmente potenciada en urbes declinantes o que se deben reinventar a propósito del debilitamiento de alguna actividad central, o la reformulación de la misma en el marco del juego de posiciones que éstas tengan, tanto al interior de las regiones, los países o la economía mundial.

La Refundación se constituye a partir del patrimonio, de un reconocimiento del pasado y de una mirada expectante. Convertirse en un polo de desarrollo es instalar una ruta del museo del carbón, museo del sindicalismo, recuperar el viejo muelle y transformarlo en un "patio de comidas", usar el hospital histórico como centro de convenciones; a ello se sumaría el ser la "capital evangélica de Chile", ya que existen más de 140 lugares de culto religioso.

\section{COMENTARIOS FINALES}

El proceso de ruptura con la cultura del carbón es un elemento central a la hora de visualizar la ciudad actual en relación con la industria del carbón y la dependencia de la vida respecto de su explotación. Ya no hay ni puede 
haber socialización tradicional orientada al trabajo en la medida en que el cierre de las minas es irrecuperable como elemento de centralidad.

Debemos asumir que subyace a Lota una potente historia ligada al trabajo en el carbón, al esfuerzo físico, al desarrollo del capitalismo en Chile, a los movimientos sociales y su épica, a los accidentes laborales y la muerte, los que sólo son referenciales a la hora de visualizarlos en su posición actual. Esto no significa que algunos intangibles no sigan vivos o que la ciudad en su materialidad no se aparezca en su referencia al carbón, sino que estos elementos tienden a ser residuales; requieren de un auditórium para ser presentados, escuchados y acogidos, por lo que hablamos de ruptura generacional y cultural, aunque desde el punto de vista antropológico, el registro mítico y la épica deben aprender a convivir con la imaginación de quienes se figuran o recuerdan el pasado.

Así, el mito representa cierta quietud, porque el mito ya no está ligado a una cierta promesa o a una cierta esperanza de futuro. Tampoco lo está en términos efectivos hacia la ciudad. Detrás de lo enunciado se observa cómo el cierre de la minas fue precipitando nuevos caminos y estrechas opciones para la población, generando un mosaico precario de alternativas y estrategias, reales o imaginarias, que son de subsistencia y sobrevivencia para hacer frente a la nueva condición postcarbón, lo que avala la idea de la resignificación socioespacial en la cual se vivía la rutina y manifestaba la sociabilidad en sus virtudes y vicios.

Hay una modificación del deber ser histórico. La palabra la toman las iglesias y no los sindicatos ni los partidos políticos. El relato de la esperanza se deposita fundamentalmente, aunque no de manera exclusiva, en la religión. Así como llegó la TV en color, la fotografía en color, también llega el azulejo de color, cerámica que sirve de revestimiento a las paredes de las casas de la ciudad, la que lava los barrios y sus murallas de su vieja historia; ya no se impregna el color del carbón y su hollín, la suciedad desaparece y con ella también se esfuma su historia y la cultura del carbón, porque el hollín que emana de las estufas es cada vez más exiguo.

Después del cierre de la mina, lo que muere es el lugar de lo masculino. Lo femenino sobrevive, ya que siempre estuvo como un eje complementario que se potencia después del cierre de la mina. Ese espacio no fue considerado relevante desde la cultura patriarcal que controlaba la mina y la ciudad; tampoco en el fracasado proceso de reconversión. Siempre fue opacado por la grandeza de la figura minera; deja de ser el fondo y se convierte en el único espacio social verdaderamente activo y relevante de la ciudad.

Enfrentamos un mundo minero sin atmósfera, en el vacío, sin función, 
de convivencia con su memoria que constituye su propio alter ego. Se transforma en la ciudad sin movimiento, sin prisa, detenida por lo errores comprometidos en el proceso de reconversión, que no previó las honduras y capas significantes que tenía el trabajo y la cultura del carbón.

Los habitantes poseen como rasgo distintivo la cualidad de organizarse. Hoy, ello no significa participación activa en las organizaciones formales, ésta se manifiesta en protesta, pero no en cuestiones propositivas respecto de la Lota que se quiere o se sueña, si es que hay espacio para ello; tampoco se muestra como construcción de ciudadanía, en lo que significa tener derechos y deberes. A partir del cierre de las minas se inculcó una modalidad de trabajo que no tiene que ver con "trabajo". En la cultura laboral de ahora, "basta trabajar con dos horas diarias", dice la gente. Otros nos informan "que los programas pro empleo son sin serrucho, sin clavos, sin cemento, ¿cómo no nos van a decir, injustamente, que somos flojos? No se puede trabajar así, sin herramientas y sin dirección."

¿Qué sentido tiene un sindicato de ex trabajadores? ¿Qué puede defender? ¿Qué puede negociar? Aunque la respuesta no es fácil, lo vigente es la capacidad organizativa, pero esta organización sólo contiene un reclamo acerca del daño a la ciudad, al modo de vida y a los cuerpos exhaustos y enfermos; allí se reclama la grandeza del oro negro en tanto aporte al país y que el ex minero debe ser compensado en tanto ex trabajador del carbón, más que por una aspiración por fuentes de trabajo presentes. Esta condición refuerza la idea de un mundo poco ciudadano y poco político en una ciudad sin esperanza. Nadie consideró el problema del tiempo libre, la ociosidad, el aburrimiento; no hay nada nuevo que conversar, especialmente dentro del hogar; no hay ya a quién reclamarle más beneficios y regalías. Lota se convierte en ciudad dormitorio, porque nunca estuvo preparada para incursionar en un futuro distinto al del carbón.

La figura o la condición reclamada es la misma que en las company town del salitre: la idea del padre piadoso, "gringo", que los abandonó. Aún con sueldos bajos, el tema de la seguridad es y fue una cuestión central, que permite seguir creyendo que en ese pasado hubo otro futuro posible.

La ciudad de Lota, creada y criada al amparo de la mina y sus quehaceres, ha quedado abandonada por aquella madre con su vientre nutriente, ha quedado al arbitrio y los avatares del destino que le ha sido negado por su condición geográfica natural, su impronta acuñada por generaciones de trabajo y lucha, así como por el desgano de los proyectos estatales de reconversión para salir de su pobreza y poder remontar los desafíos del siglo XXI. Lota es una ciudad dañada, expulsora y residual. 


\section{REFERENCIAS}

Alcalde, Alfonso (1973). Reportaje al carbón. Santiago, Chile: Editorial Quimantú.

Aravena, José y Claudio Betancur (1999). "Crisis y reconversión laboral del carbón”. Proposiciones Vol. 27, Santiago de Chile, Ediciones Sur. http://www. sitiosur.cl/r.php?id=566. [Consultado el: 14.10.2010].

Astorquiza, Octavio (1952). "El centenario de Lota", en Octavio Astorquiza y Oscar Galleguillos, Cien años del carbón de Lota. 1852 - septiembre - 1952 (pp. 15-16). Santiago de Chile: Compañía Carbonífera Industrial de Lota.

Baeza, Manuel Antonio (2008). Mundo real, mundo imaginario social. Teoría y práctica de sociología profunda. Santiago, Chile: Ril Editores.

Corvalán, Gregorio (1992). "Modo de vida de los mineros del carbón. Golfo de Arauco", en Mundo Minero. Chile, siglos XIX y XX (pp. 125-150). Santiago, Chile: Universidad de Santiago de Chile.

De Dinechin, Philippe (2001). Identidad y reconversión en las ciudades carboníferas de Lota y Coronel - Chile. Concepción, Chile: Fundación Cepas.

Di Tella, Torcuato; Brams, Lucien; Reynaud, Jean-Daniel y Touraine, Alain (1966). Huachipato et Lota: Etude sur la Conscience Ouvriere dans deux Entreprises Chiliennes. Paris, Francia: Editions du Centre National de la Recherche Scientifique.

Figueroa, Consuelo (2009). Revelación del subsole. Las mujeres en la sociedad minera del carbón. 1900-1930. Santiago de Chile: ICSO, Centro de Investigaciones Diego Barros Arana, Ediciones de la DIBAM.

Galleguillos, Oscar (1952). "La epopeya del carbón”, en Astorquiza, Octavio y Galleguillos, Oscar, Cien años del carbón de Lota. 1852 - septiembre - 1952 (pp. 17-28). Santiago de Chile: Compañía Carbonífera Industrial de Lota.

Hobsbawm, Eric (2002). "Introducción: la invención de la tradición", en Hobsbawm, E. y Ranger, T., La invención de la tradición (pp. 7-21). Barcelona, España: Editorial Crítica.

Lillo, Baldomero (2009). Obra completa. Edición preparada por Ignacio Álvarez y Hugo Bello. Santiago, Chile: Biblioteca Chilena de Ediciones de la Universidad Alberto Hurtado.

Medina, Patricio (2010). "La espera como forma alienada del sufrimiento humano. La historia interrumpida de un pueblo minero", en Bilbao, Alejandro y Morlans, Ignacio (editores), Duelo, pérdida y separación: Figuras del sufrimiento humano (pp. 117-128). Valparaíso, Chile: Ediciones Universitarias de Valparaíso.

Ortega, Luis (1992). "El mundo del carbón en el siglo XIX”, en Orellana Muerman, Marcela y Muñoz Correa, Juan G. (Eds.), Mundo minero. Chile, siglos XIX y XX. Santiago: Universidad de Santiago de Chile, 101-124.

Rivas, Gonzalo (2000). "Prólogo", en Vega, Pascual, Once días bajo tierra. Coronel, Chile: Imprenta San José. 
Rodríguez, Juan Carlos (2010). "De la ciudad del trabajo a la ciudad del vacío: el lugar del sufrimiento", en Bilbao, Alejandro y Morlans, Ignacio (editores), Duelo, pérdida y separación: Figuras del sufrimiento humano (pp. 91-106). Valparaíso, Chile. Ediciones Universitarias de Valparaíso.

Rodríguez, Juan Carlos y Miranda, Pablo (2010). "Identidad, transformación y retórica patrimonial en una ciudad minera del Desierto de Atacama, Chile", en Desacatos. Revista de Antropología Social, mayo-agosto (pp. 151-166). México D.F. Ciesas.

Román, José (1970). Reportaje a Lota (documental). Fotografía: Diego Bomnacina; montaje: Carlos Plaggio; voz en off: Marta Contreras. Departamento de Cine de la Universidad de Chile de Valparaíso - Central Única de Trabajadores.

Saramago, José (2008). La caverna. Madrid, España: Editorial Santillana.

Vega, Pascual (2000). Once días bajo tierra. Coronel, Chile: Imprenta San José. Venegas, Hernán (2008). El carbón de Lota. Textos y fotografías a fines del siglo XIX. Las visiones de Francisco Marcial Aracena y Guillermo E. Raby. Santiago, Chile: Editorial Pehuén. 